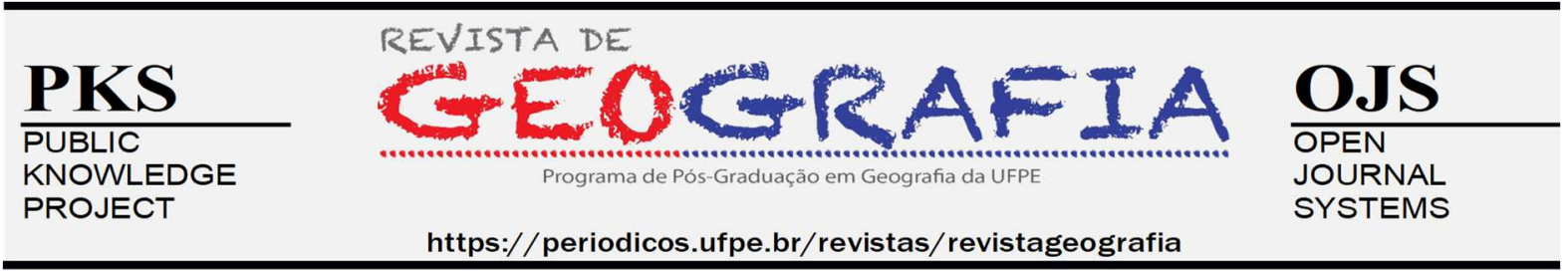

\title{
UMA ANÁLISE HISTÓRICO-CULTURAL DO PROCESSO DE CRIAÇÃO E FORMAÇÃO DO MUNICÍPIO DE TRIUNFO - PB
}

\author{
Thinaly Suellen Sousa Machado ${ }^{1}$, José Lindemberg Bernardo da Silva ${ }^{2}$, Franklin Roberto da \\ Costa $^{3}$
}

${ }^{1}$ Universidade Regional do Cariri (URCA). Licenciada em Geografia pela Universidade Regional do Cariri (URCA) e Bacharela em Ciências Jurídicas pela Faculdade de Filosofia, Ciências e Letras de Cajazeiras (FAFIC). Esp. em Direito do Trabalho e Direito Previdenciário, pela Universidade Regional do Cariri (URCA). E-mail: thinaly.ts@gmail.com; http://orcid.org/0000-0002-8761-259X

${ }^{2}$ Licenciado em Geografia pela Universidade Federal de Campina Grande (UFCG). Licenciado em Pedagogia pelas Faculdades Integradas do Ceará (UniFIC). Pesquisador e Mestrando em Planejamento e Dinâmicas Territoriais no Semiárido pela Universidade do Estado do Rio Grande no Norte (UERN). E-mail: bergbernardo.s@gmail.com; http://orcid.org/0000-0003-4090-6440

3 Doutor em Desenvolvimento e Meio Ambiente - PRODEMA/RN. Pesquisador, Professor Adjunto IV do Departamento de Geografia e Professor do Programa de Pós Graduação em Planejamento e Dinâmicas Territoriais do Semiárido da Universidade do Estado do Rio Grande do Norte (UERN). E-mail: franklincosta@uern.br; http://orcid.org/0000-0001-7708-0668

Artigo recebido em 31/01/2021 e aceito em 04/05/2021

\section{RESUMO}

O presente trabalho tem como objetivo analisar os processos de criação e de emancipação política do município de Triunfo, localizado na mesorregião do Sertão Paraibano. Para tal, utilizamos referenciais bibliográficos específicos que tratam dos processos em estudo. Para consubstanciar a análise, recortamos categorias relacionadas ao espaço urbano e à história local, com base em estudiosos da área. Por fim, registramos uma breve caracterização do processo de formação urbana da sede do município, e posteriormente, recortamos eventos históricos e fatores socioeconômicos correlacionados ao processo de formação do município em destaque.

Palavras-chave: criação; formação; município; história; Triunfo.

\section{A HISTORICAL-CULTURAL ANALYSIS OF THE PROCESS OF CREATING AND FORMING THE MUNICIPALITY OF TRIUNFO - PB}

\begin{abstract}
This work aims to analyze the processes of creation and political emancipation of the municipality of Triunfo, located in the mesoregion of the Sertão Paraibano. For that, we use specific bibliographic references that deal with the processes under study. To substantiate the analysis, we cut out categories related to urban space and local history, based on researchers in this area. Finally, we record a brief
\end{abstract}


characterization of the urban formation process at the municipality's headquarters, and later, we cut out historical events and socioeconomic factors correlated to the process of formation of the highlighted municipality.

Keywords: creation; formation; county; history; Triunfo.

\section{UN ANÁLISIS HISTÓRICO-CULTURAL DEL PROCESO DE CREACIÓN Y FORMACIÓN DEL MUNICIPIO DE TRIUNFO - PB}

\section{RESUMEN}

Este trabajo tiene como objetivo analizar los procesos de creación y emancipación política en el municipio de Triunfo, ubicado en la mesorregión del Sertão Paraibano. Para ello, utilizamos referencias bibliográficas específicas que tratan de los procesos en estudio. Para fundamentar el análisis, cortamos categorías relacionadas con el espacio urbano y la historia local, en base a expertos en el área. Finalmente, registramos una breve caracterización del proceso de formación urbana de la cabecera municipal, y posteriormente, recortamos hechos históricos y factores socioeconómicos correlacionados con el proceso de formación del municipio destacado.

Palabras clave: creación; formación; condado; historia; Triunfo.

\section{INTRODUÇÃO}

A linha de pesquisa apresentada neste trabalho é voltada para um contexto de resgate histórico como fator ligado ao processo de urbanização, entreposto ao evento social de formação e emancipação política abordando, principalmente, as categorias espaço geográfico e urbano.

Por meio deste estudo, buscamos contribuir com a caracterização, no tempo e no espaço, dos processos de formação e de expansão urbana da cidade de Triunfo-PB, evidenciando os eventos e os elementos que contribuíram para esses processos, a partir de análises documentais e das transformações verificadas no seu espaço intraurbano.

O método utilizado na pesquisa é o materialismo histórico-dialético, por meio do qual buscamos explicar a totalidade da realidade de Triunfo, a partir da interpretação das particularidades do objeto de estudo, bem como da compreensão dos processos sociais que ocorreram para a formação do município.

A realização da pesquisa justificou-se em virtude das poucas pesquisas acadêmicas sobre os processos de formação e de urbanização de Triunfo. Dentre essas pesquisas, citam-se Andrade (2008), Mangueira (2011), Dantas (2013) e Abreu (2015). Além desses autores, em 
nossa pesquisa bibliográfica, encontramos uma série de publicações não acadêmicas, a exemplo de documentos municipais, crônicas e outros gêneros literários acerca do município em questão.

Para tanto, apresentou-se aqui, o processo histórico de criação e formação do Município de Triunfo-PB, analisando os referenciais teórico-conceituais e algumas fontes documentais, apresentando-se a importância dos eventos sociais e políticos para constituição e surgimentos do município, se efetivando como um trunfo para a sua sociedade, nos termos discutidos, principalmente, por Bezerra (2016) e Abreu (2015).

\section{DO PEQUENO POVOAdo DE PICADAS À FORMAÇÃo DO DISTRITO DE TRIUNFO}

No que se remete à localização e acesso ao município de Triunfo/PB, de acordo com o Plano Diretor Participativo de Triunfo-PB (BRASIL, 2012), o referido localiza-se no extremo oeste da Paraíba, apresentando os seguintes limites territoriais: a) norte: Bernardino Batista; b) oeste: Umarí no estado do Ceará; c) sul: Santa Helena; d) leste: Poço de José de Moura; e) e ao nordeste: Joca Claudino (Figura 1).

Figura 1: Mapa da localização do município de Triunfo no Estado da Paraíba

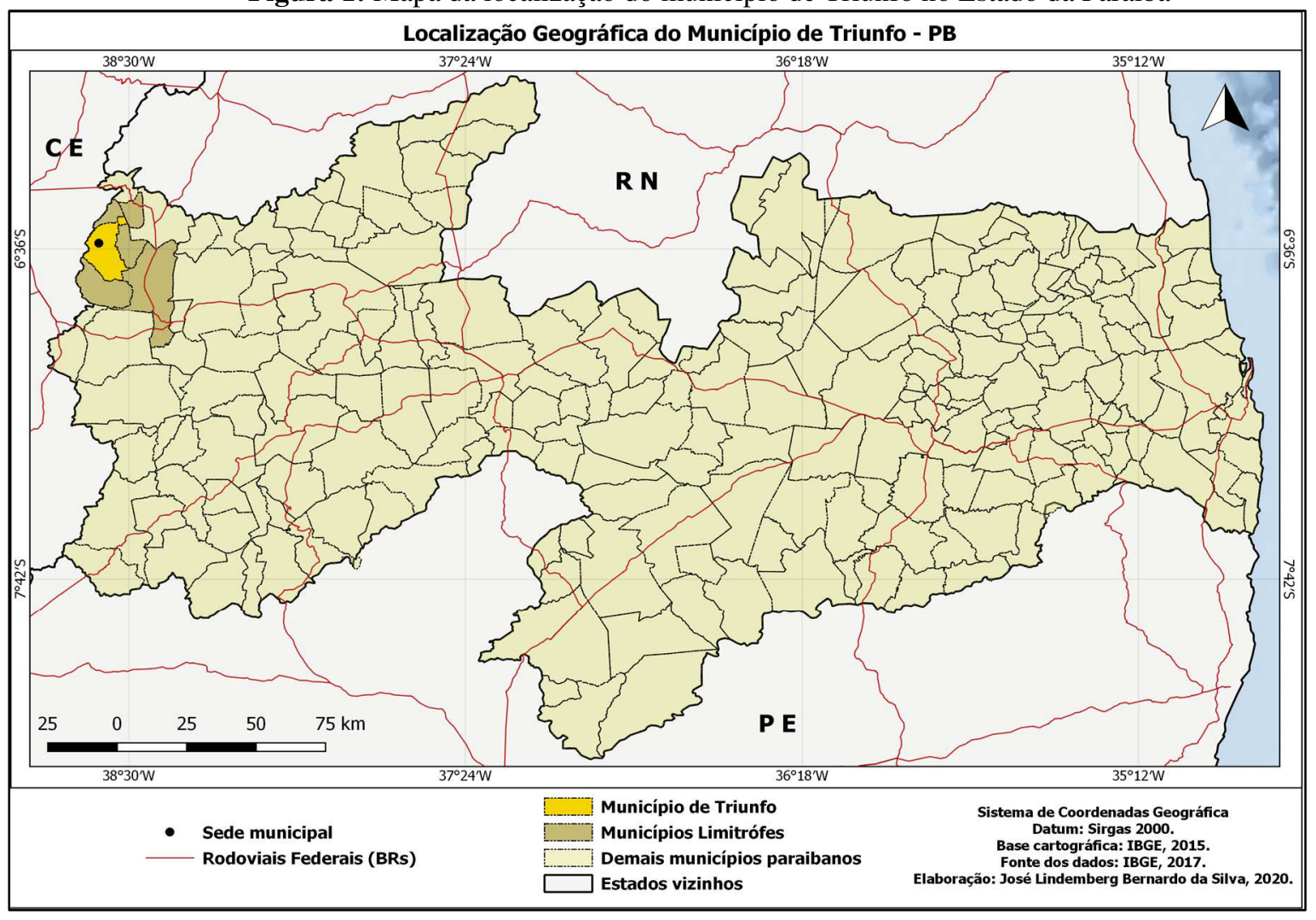

Fonte: Silva, 2020. 
A cidade de Triunfo, não diferente da maioria das cidades brasileiras, apresenta um processo evolutivo desordenado, passando por vários status, até chegar a sua formação de distrito, iniciando com a formação de um pequeno povoado às margens de um olho d'água chamado Gamellas. Abreu (2015, n.p.) afirma que:

[...] os primitivos povoadores do sertão, ao mesmo tempo em que se sentiam atraídos pela abundância de terras, buscavam encontrar refrigério para as suas boiadas. Entre estes colonizadores estavam Domingos Jorge Rodrigues que, em 1752, ao requerer data de sesmaria, dizia ter descoberto "um olho d'água chamado das Gamellas que nasce da serra que extrema com o sertão do Jaguaribe e pelo poente contesta com a fazenda do Humary [...] e pela parte da nascente com a fazenda do Brejo" e, por isso, requeria três léguas de comprido e uma de largura "para criar seus gados e plantar lavouras".

O início da ocupação das terras se deu por boiadeiros, no ano de 1752, data que se requeria as sesmarias e que, nesse caso, segundo o autor supracitado, foram colonizadas por Domingos Jorge Rodrigues. Estas terras serviram como rotas para levar a boiada até a cidade de Icó, no vizinho estado do Ceará.

Ainda de acordo com Abreu (2015), esta terra tão desejada pelos boiadeiros, foi concedida como um núcleo inicial de povoamento em 12 de fevereiro de 1752, através do governo de Antônio Borges da Fonseca, a qual foi nomeada como fazenda Gamellas. A partir daí, Domingos Jorge Rodrigues, reconhecido pelo o autor como um dos principais colonizadores destas terras, começou a introduzir equipamentos, tais como: casas de residência, currais para abrigo do gado, roçados, estabelecendo os primeiros traços para a fundação efetiva da localidade.

Em consequência da introdução desses equipamentos, essa localidade atingiu o status de povoamento e efetivando, assim, o processo de ocupação impulsionado pela abertura de estradas, construções de residências e outros equipamentos.

Um povoamento pode assim albergar tanto um pequeno número de habitações agrupadas num reduzido espaço, lugares, aldeias ou vilas, como vastas áreas urbanizadas, as cidades. Num sentido tradicional, um povoamento inclui bens urbanos como caminhos, estradas, ruas, recintos, campos, lagos, poços, moinhos, igrejas etc. (EDUCALINGO, 2018, n.p.).

Uma das rotas desenvolvidas pelos boiadeiros com objetivo de conquistar o sertão paraibano foi a $4^{\circ}$ Linha, de Domingos Jorge, responsável pelo início do povoamento destas 
terras. Essa rota tornava-se importante, por fazer uma interligação entre as terras no vale do Piancó, passando pelo Rio do Peixe e Formiga, cujo destino seria o estado do Piauí (Figura 2).

Figura 2: Mapa das Linhas de Penetração na conquista dos sertões paraibanos, com destaque para linha 4

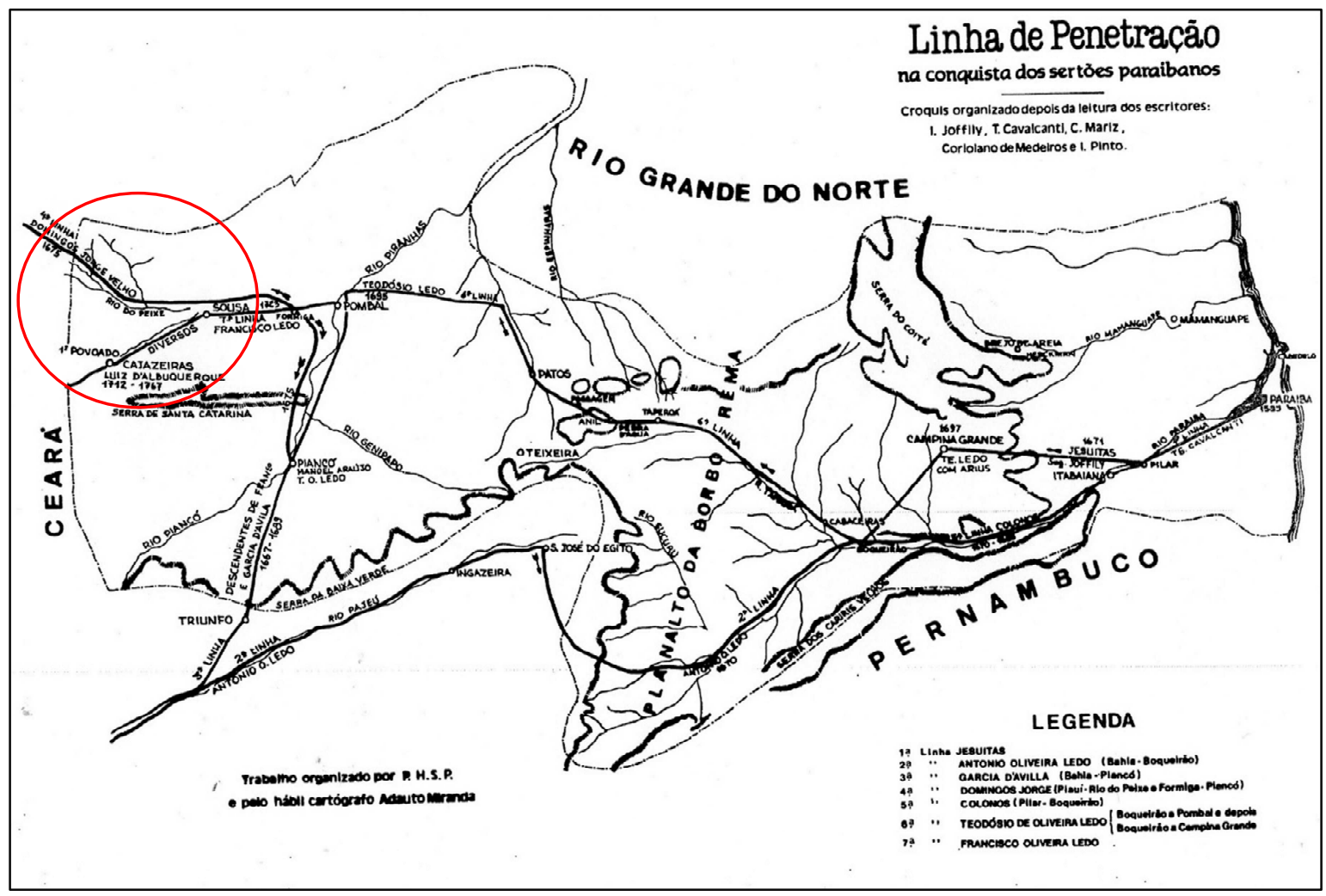

Fonte: Heliodoro (1991).

Além de servir como rota acessível para os boiadeiros e colonizadores, essas terras apresentavam-se como um lugar hábil para a construção de moradias. Um exemplo disso era a facilidade de estarem próximos a um olho d'água considerado, até os dias atuais, como um lugar ideal para o desenvolvimento de roçados e a criação de gado.

Com o passar dos anos, por volta do século XIX, o Sítio Gamelas já se apresentava como um povoado consolidado, dando-se sua criação, segundo Abreu (2015), em 08 de novembro de 1803, da Companhia do Distrito do Riacho das Gamelas, Serras do Padre José Gomes e Luís Gomes, dos quais todos faziam parte do Corpo de Infantaria da Ordenança da Vila Nova de Sousa. Na época, foi indicado para capitão-mor desta companhia, pelo Senado da Câmara de Sousa, o Alferes Domingos João Dantas Rothea, residente na povoação de São João do Rio do Peixe. 
Dessa forma, as terras que antes pertenciam à sesmaria de Domingos Jorge Rodrigues, passaram ao comando do capitão-mor Domingos João Dantas Rothea e, consequentemente, pertencendo, de forma legítima, ao povoado de São João do Rio do Peixe.

Com o passar do tempo, novas fazendas e povoados foram surgindo nas redondezas, a exemplo da Vila de Icó, no estado do Ceará, ocupada pelo Capitão Agostinho José Tomaz de Aquino. Segundo Abreu (2015), esse capitão se tornou proprietário da fazenda Picada, local em que se formou uma povoação. A partir de então, se inicia um processo de confronto e guerra entre imperialistas e republicanos no dia 17 de outubro de 1824. Nesta fazenda, a vitória de um seria um dos motivos para renomear à localidade. Estes confrontos ficaram conhecidos como a Confederação do Equador.

\begin{abstract}
O nome deve-se a uma batalha ocorrida em seu solo em 17 de outubro de 1824, por ocasião de um confronto entre os Confederados, grupo revolucionário separatista que lutava pela formação de uma confederação nos estados da Paraíba, Ceará, Rio Grande do Norte e Piauí e as tropas governistas que defendiam a integridade nacional sob o domínio do império. Após o início da repressão ao movimento ocorrido em Recife, comandados pelo líder religioso Frei Caneca do Amor Divino, os confederados saíram pelo interior tentando apoio para a sustentação do intento, ocorrendo várias batalhas travadas entre estes e tropas oficiais. Em um desses confrontos o último antes da prisão de Frei Caneca na Fazenda Juiz, em Missão Velha$\mathrm{CE}$, houve um verdadeiro extermínio com a baixa de cento e oitenta homens do grupo separatista. Isso motivou os imperialistas a denominarem a localidade em que houve a batalha, de Triunfo - até então conhecida por Picadas - em homenagem ao feito militar ali ocorrido (MANGUEIRA, 2011, p. 18).
\end{abstract}

Como referenciado, a mudança do nome daquele povoado estava ligada à confrontos e guerras. Para Mendonça (2018), esses eventos foram de grande importância para a formação urbana da localidade.

Conforme os referenciais consultados, durante todos os eventos aqui apresentados, o, até então, povoado Triunfo, ainda pertencia ao município de Antenor Navarro (atual São João do Rio do Peixe). Esse município tinha poder político e domínios eclesiásticos sobre várias povoações além de Picadas (nome anterior do atual Triunfo), como é o caso do distrito de Belém do Arrojado (atual Uiraúna), e também de uma localidade próximo a Picadas, chamada de Barra do Juá, local que já apresentava uma pequena formação urbana, e já era considerada uma das povoações mais populosas.

Foi na povoação de Barra de Juá que o domínio eclesiástico de São João do Rio do Peixe começou a construir capelas para eventos religiosos, contribuindo, assim, para aumentar 
a população da localidade. Vale ressaltar que essa localidade não chegou a se emancipar e que, atualmente, pertence ao município de Triunfo.

O Padre José Gonçalves Dantas depois de ter empreendido grande esforço na construção da Igreja do Rosário da Povoação de São Joao, voltou-se para o próspero Povoado da Barra do Juá, construindo ali a capela de Nossa Senhora da Conceição no ano de 1858. Anos depois, esse templo foi ampliado e um cemitério construído através de uma campanha realizada pelo missionário padre Ibiapina (ABREU, 2015, p. 290291).

A construção do cemitério na povoação de Barra do Juá impulsionou o aumento da população circunvizinha do povoado de Triunfo. Os anos passaram e muitas famílias, fizeram da vila de Picadas o seu lugar de moradia. Nesse período, a economia dessa pequena vila era baseada na agricultura de subsistência e na criação de gado.

Outro ponto discutido por Abreu (2015), é que, por não haver recursos médicos, muitos eram afetados por enfermidades e quase sempre chegavam a óbito por não receberem o devido tratamento. Segundo o autor, isso se deve, não somente ao isolamento do povoado, mas também ao negligenciamento da gestão pública, localizada na sede municipal, em relação às necessidades básicas do distrito formado no final dos anos de 1950.

Ainda no século XIX, para reforçar a mudança do nome da vila de Picadas, ocorreu um evento religioso, o qual foi de extrema relevância para a consolidação da criação de um núcleo urbano. Além disso, também foi marcado por apresentar, nessa mesma época, a última construção de uma capela das povoações pertencentes ao domínio eclesiástico de São João do Rio do Peixe.

\footnotetext{
A última capela construída e pertencente aos domínios eclesiásticos de São João do Rio do Peixe foi o templo dedicado ao Menino Deus, localizado no antigo Povoado de Picadas (atual Triunfo). Ali, um beato conhecido como caboclo Manoel Bernardo, temendo que a epidemia de cólera atingisse a localidade, recorreu ao Menino Deus, fazendo-lhe uma promessa de que se o lugarejo fosse poupado de tal calamidade, ele ergueria uma pequena capela e celebraria a sua festa todos os anos. Tendo alcançado a graça, o Caboclo Manoel saiu pelas redondezas pedindo esmolas e levantando recursos para construção, que em 1874 ainda estava inacabada, não passando de uma pequena “casa d'oração". As obras de edificação continuaram até 24 de junho de 1881 , quando, depois da conclusão dos trabalhos, o caboclo Manoel Bernardo convidou o Cônego Manoel Vieira da Costa e Sá, então vigário da Freguesia de São João, para celebrar uma missa e solenemente abençoar a nova capela. [...] o cônego Costa "dirigiu a palavra às pessoas ali presentes e declarou que daquele dia em diante ali não seria mais sitio Picadas e sim Triunfo”. (ABREU, 2015, p. 304).
} 
A citação acima nos mostra o surgimento do principal evento cultural-religioso o qual, segundo o autor, foi uma das principais razões para renomear a localidade e que logo se apresentaria como atrativo turístico, o que veio a se confirmar anos depois.

A historiografia local aponta que esses foram os dois principais eventos para que Triunfo obtivesse o referido nome, sendo os eventos: a Confederação do Equador (no ano de 1824) e a construção da Capela (no ano de 1881). Consequentemente, o crescimento populacional foi se dando de forma paulatina, conformando-o à categoria de distrito. Porém, não foi neste período que ocorreu a transição, ficando ainda conhecido como vila, ao entorno do distrito de Barra do Juá, o qual já apresentava uma característica de formação urbana mais avança à época.

Anos depois, em 1937, a capela foi demolida e reconstruída, para que viesse atender a necessidade da população e dando, assim, uma maior dimensão à sua importância como equipamento que contribuiu para o aumento da aglomeração populacional na vila. A capela foi um importante equipamento urbano para o surgimento das primeiras ruas e edificações de moradias. Isso porque muitas pessoas começaram a se deslocar de outros lugares para morar neste povoado, dando o aumento da população e, consequentemente, das construções residenciais nas ruas que davam acesso à capela. Como citou Abreu (2015, n.p.): "até mesmo a feira que outrora acontecia no Distrito da Barra do Juá, foi transferida para Triunfo".

Ao passar do tempo, a população da referida localidade vai aumentando e, com isso, há a necessidade de reformar a capela para comportar o número crescente de fiéis. É possível observarmos, na figura 1, a construção da torre da capela, que logo viria a ser estabelecida como paróquia local.

Com a transferência da feira para Triunfo, a população continuava a aumentar e a economia começava a se desenvolver ali. Nesse caso, segundo Abreu (2015), a feira se constituiu como uma chave para o desenvolvimento da localidade.

Mangueira (2015) afirma que estes foram alguns dos principais eventos sociais ocorridos na vila para dar início ao processo de formação urbana de Triunfo. Segundo o autor, anos depois, percebeu-se a chegada de uma nova cultura na vila, propiciando a introdução de novos elementos, tal como a criação de novas ruas, que anos depois passaram a integrar o perímetro urbano. 
Figura 1: Construção da torre da Igreja Matriz do Menino Deus

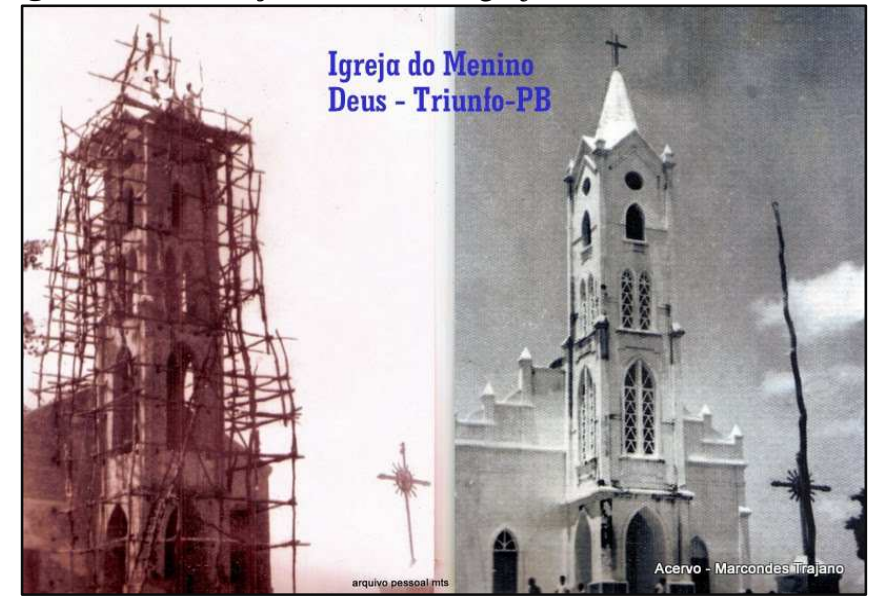

Fonte: imagens gentilmente cedidas, por Marcondes Trajano.

Com o passar do tempo, especificamente na década de 1950, Triunfo vai ganhando novos moradores e a sua população vai crescendo consideravelmente. Para marcar esta época, ocorreu a chegada dos "Os Quarentas"; um grupo de negros vindo da cidade de Pombal em busca de um lugar para que pudessem construir uma nova vida e desenvolver suas culturas.

Andrade (2008, p. 42) afirma “[...] que no ano de 1951, por questões ligadas a conflitos envolvendo a propriedade da terra, migraram, para o município de Triunfo e aqui chegaram em número de 40 pessoas, e que ficaram conhecidos na localidade como os negros dos 40".

A chegada desses quilombolas na povoação de Triunfo provocou um acréscimo no contingente populacional, além de incrementar a cultura local, criando uma banda música, conhecida como Cabaçal. Essa banda, durante as festas do padroeiro da cidade, integravam os momentos das procissões com louvores e batucadas. Com isto, admitimos a importância da chegada desse grupo afrodescendente na vila.

Ainda sobre esse grupo, outro aspecto que merece destaque foi às lutas travadas nas terras de Pombal, lugar de saída desse grupo. Os Quarentas conseguiram conquistar o seu lugar, e, por conseguinte, delimitarem seu território para se fixarem e construírem a vida que tanto almejavam: tranquilidade e paz. Esses "novos moradores" desenvolveram suas casas distantes

\footnotetext{
${ }^{1}$ Nome dado aos 40 negros remanescentes do Quilombo de Pombal - PB, que atualmente estes remanescentes contam com uma sede onde guarda toda a sua história, a Sede do Quilombo dos Quarentas, localizada na Cidade de Triunfo (ANDRADE, 2008).
} 
da capela, mais precisamente, em uma porção noroeste do território do povoado o qual logo viria a compor sua zona urbana.

Com o passar do tempo, a soma de vários eventos sociais e culturais, deram ao povoado características de um distrito. Ou seja, ela já começa a causar influências sobre povoações menores. Todavia, ainda não poderia receber esta nomenclatura, pelo fato de que São João do Rio do Peixe ter como seu distrito o Brejo das Freiras, local que tinha um desenvolvimento de elementos urbanos que chamava a atenção da economia.

Vários fatores político-sociais não permitiam que o povoado de Triunfo fosse elevado à condição de distrito sendo, um desses fatores, a falta de infraestrutura. Segundo Pinto (2003, p. 57), "o distrito é uma subdivisão do município, que tem como sede a vila, que é um povoado de maior concentração populacional”.

Na década de 1950, o estado da Paraíba viveu uma "onda" emancipatória. Vários distritos começavam a se tornar cidades e suas vilas se tornavam distritos. No entanto, existia algo que impedia a elevação do povoado de Triunfo à cidade: àquela época, era necessário passar à condição de distrito, título pertencente ao distrito Brejo das Freiras, o qual possuia um popular Hotel, conhecido por suas famosas fontes termais (ABREU, 2015).

A luta dos produtores agropecuários, a economia e a população crescentes foram as justificativas dadas pelos vereadores representantes de Triunfo na Câmara Municipal de São João do Rio do Peixe que, consequentemente, conseguiram elevar Triunfo à condição de distrito, fato este que ocorreu por meio da Lei no 145 de 24 de junho de 1957, sancionada pelo, então prefeito, Manuel Fernandes Dantas.

\footnotetext{
Os vereadores que representavam os interesses dos habitantes de Triunfo no legislativo sãojoanense cuidaram de elaborar um projeto de lei, que revogava a criação do Distrito de Brejo das Freiras e criava o de Triunfo. A justificava principal para tanto, era sem dúvida, o desenvolvimento adquirido pela próspera vila, em termos populacionais e econômicos. Assim, em 24 de junho de 1957 era sancionada a Lei ${ }^{\circ}$ 145, assinada pelo então prefeito Manuel Fernandes Dantas (ABREU, 2015, n.p.).
}

Por fim, Triunfo é elevado à condição de distrito. Posteriormente, o novo processo seria conseguir a sua emancipação política-administrativa, ou seja, tornar-se município. 


\section{PROCESSO EMANCIPATÓRIO: DE DISTRITO À MUNICÍPIO}

O ponto relevante do processo emancipatório do município Triunfo ocorreu no final da década de 1950, poucos anos depois de ter sido elevada à distrito. As mobilizações da população triunfense começavam a ganhar força e destaque pela região, cujo o objetivo dessas mobilizações era o desmembramento e a autonomia do município de São João do Rio do Peixe.

Segundo Pinto (2013, p. 29):

[...] o município é a menor unidade territorial brasileira com governo próprio, é formado pelo distrito-sede, onde acha-se localizada a cidade, que é a sede municipal e que leva o mesmo nome do município e, que corresponde à zona urbana municipal e; também, pelo território ao seu entorno, a zona rural municipal, que pode ser dividida em distritos, cuja maior povoação recebe, geralmente, o nome de vila.

Com o aumento das manifestações e com Triunfo elevada à condição de distrito, os processos voltados para a emancipação política se desenvolveram no plano legislativo estadual. Para isso, foi necessário um apoio político que levasse o respectivo projeto até a bancada da Câmara da Assembleia Legislativa. Segundo Abreu (2015), o Deputado cajazeirense Acácio Braga Rolim, foi quem concedeu apoio aos triunfenses, em troca de apoio político nas próximas eleições pois, à época, o estado ganhava altos investimentos quando emancipava novos municípios.

O ponto de partida para a emancipação política de Triunfo ocorreu a partir de uma reunião na casa de um dos líderes deste processo, o "senhor Joaquim Moreira e Silva, a qual era localizada na rua hoje denominada de Sete de Setembro" (ANDRADE, 2017, p. 48). Joaquim era um dos principais envolvidos no processo do desmembramento do distrito de Triunfo de São João do Rio do Peixe.

Durante essa reunião se fizeram presentes políticos e personalidades locais. Segundo Andrade (2017, p. 48), marcaram presença o Deputado Acádio Braga, responsável pela apresentação do projeto na bancada legislativa estadual, os senhores Joaquim Moreira e Silva, Raimundo Donato de Oliveira (vereador à época) e Antônio Adriano de Andrade, os quais integraram a comissão responsável pela delimitação geográfica do novo município, assumindo todos os trabalhos burocráticos e a articulação política. 
No dia 22 de dezembro do ano de 1961 foi sancionado, pelo Governador Pedro Moreno Godim, a Lei $\mathrm{n}^{\mathrm{o}} 2.367$, que consolidou a independência política ao novo município paraibano, Triunfo. E assim, foi deliberada:

Faço saber que o Poder Legislativo decreta e eu sanciono a seguinte Lei:

Art. $1^{\circ}$ - Fica criado o município de Triunfo, desmembrado do município de Antenor Navarro, com sede na atual vila do mesmo nome que fica elevada a categoria de cidade (PARAÍBA, 1961).

O município recém-criado poderia conformar os seus próprios limites geográficos como é apresentado na Lei Estadual no 2.367/61:

\begin{abstract}
Ao Norte pelo município de Uiraúna;
Ao Oeste com o Estado do Ceará;

Ao Sul com o Distrito de Santa Helena;

Ao Leste a partir do Rio do Peixe, do ponto em que toma o nome de Rio do Brejo, segue pela estrada carroçável até os Sítios Carretão e Genipapeiro, de onde segue o rumo ao Norte, passando pela frente da casa de Valdivino Batista e pela divisão dos Sítios Genipapeiro e alho D'Agua até a estrada de Triunfo; seguindo, divide os Sítios Olho D'Agua e Pedro da Costa; ainda rumo ao Nascente, divide as terras de Pedro da Costa com as de Júlio Cândido e José Duarte. Neste mesmo rumo, segue os limites dos Sítios Barra de Juá, e Poço, incluindo-se no mesmo município as terras de Estácio de Sá e Vicente Estanislau até as de Domiciliano Francisco de Oliveira. Seguindo rumo ao Norte, vai ter aos limites das terras do mesmo Domiciano, e, seguindo ao Nascente, atinge a linha divisória do município de Uiraúna, que tem como rumo certo a Lagoa Bartolomeu, seguindo esta linha até encontrar os limites Sul do município de Uiraúna, ficando esclarecido que pertencerão ao novo município os povoados de Barra de Juá e Serra do Padre (PARAÍBA, 1961).
\end{abstract}

Depois de um longo período, Triunfo finalmente é elevado à categoria de município, tornando-se politicamente independente do município de São João do Rio do Peixe. Daí em diante, dava-se início a uma nova conformação urbana.

Os eventos político-sociais ocorridos à época constituíram-se como fatores que possibilitaram impulsionar a elevação de Triunfo a município, ocorrendo em pouco tempo, entre a formação de distrito e a emancipação política, dentre outros eventos. 


\section{O TERRITÓRIO MUNICIPAL COMO UM TRUNFO}

O desenvolvimento de novas caraterísticas socioespaciais começam a ocorrer no espaço urbano de Triunfo a partir do surgimento, dentre outros fatores, de uma estrutura política mais consolidada e de novos arruamentos e bairros.

A cidade, agora consolidada no município emancipado, pode ser conceituada em diferentes pontos de vista. Marx e Engels (1984, p. 64 apud VASCONCELOS, 2006), em sua obra a Ideologia Alemã, tratam o termo cidade sob uma perspectiva bastante positiva. Para eles, cidades são como "a realidade de concentração da população, de instrumentos de produção, dos prazeres e das necessidades [...]", enquanto que o campo seria seu oposto.

Podemos, então, descrever a cidade a partir da citação acima, como lugar onde se apresenta a concentração de um maior contingente populacional com características urbanas ligadas a determinados meios de produção, prazeres e como forma especial de reprodução e de consumo de necessidades específicas de uma sociedade.

Vasconcelos (2006, n.p.) relata que, de acordo com o geógrafo F. Ratzel (1891), a cidade se apresenta como uma forma concreta, uma "reunião de homens e habitações humanas, cobrindo uma grande superfície e situada nos cruzamentos das grandes vias comerciais".

Nesse sentido, podemos destacar a cidade, também, como um local que se desenvolvem vias comerciais, servindo, em muitos casos, como ponto de encontro para o desenvolvimento das práticas comerciais. Em uma escala menor, vemos a presença das feiras nas cidades, trazendo, porém, do campo, os seus produtos a comercializar, ou seja, da zona rural, como é o caso de Triunfo.

Vasconcelos (2006, n.p.), descreve que, no ano de 1921, na Europa, a cidade era vista como uma comunidade urbana e que se apresentava como "um habitat concentrado, uma grande localidade", a qual era vista, economicamente, como "uma aglomeração cuja maior parte dos habitantes vive da indústria e do comércio, e não da agricultura".

Utilizando-se do conceito acima para descrever a cidade de Triunfo, atualmente, já não seria a conceituação ideal, pois a cidade ainda tem uma forte ligação com o setor primário da economia. Ou seja, o maior contingente populacional não se concentra na sede do município, mas na zona rural. Isso é o que podemos observar no gráfico 1. 
Gráfico 1: Total da população municipal (\%) no ano de 2010.

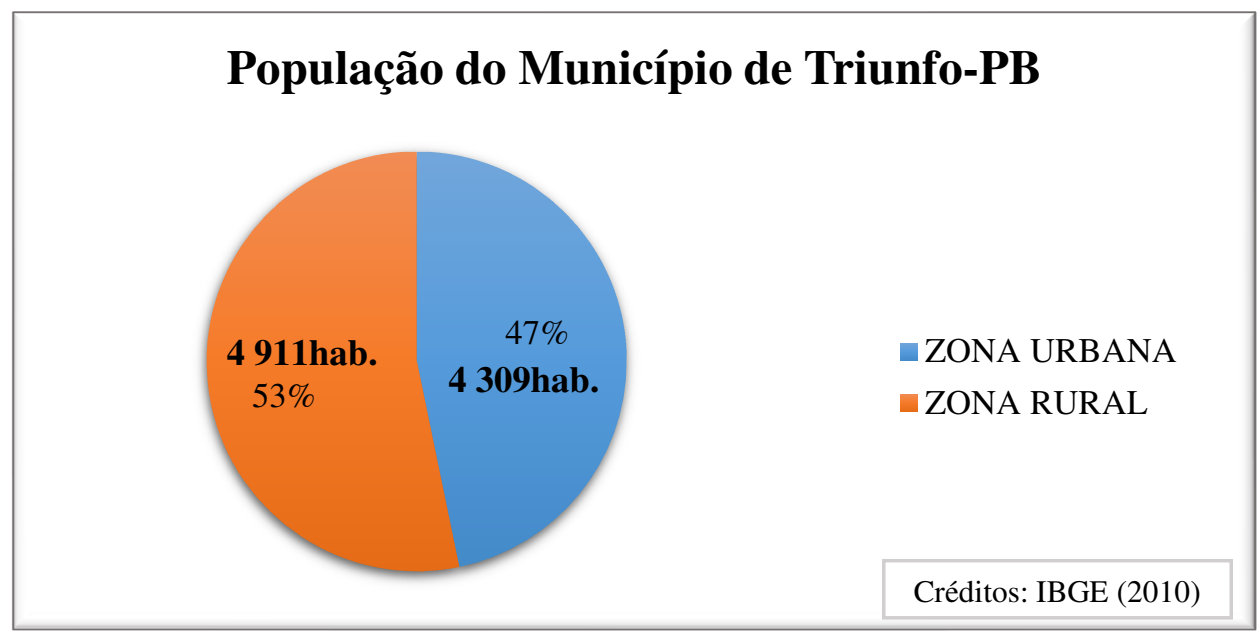

Fonte: Dados do Censo Demográfico do IBGE, 2010. Organizado pelos autores.

O termo cidade é algo que apresenta grandes discussões em relação ao seu conceitual, pois cada pensador teórico apresentará concepções diferentes em relação à mesma.

Segundo Vasconcelos (2006, n.p.), George P. (1952) afirma que a cidade seria descrita como "um fato histórico e um fato geográfico, na medida em que sua forma seria um compromisso entre o seu passado e o presente, enquanto que o seu conteúdo humano e a atividade de seus habitantes seriam marcados pelo signo do presente".

Santos (1994, p. 69) apresenta a cidade de forma contraposta ao urbano, sendo a cidade como "o particular, o concreto e o interno" e o urbano seria "o abstrato, o geral e o externo".

Por muitas vezes, entender a dinâmica de uma cidade torna-se menos complexo quando nos detemos ao conceito geográfico de paisagem e suas variadas classificações, tais como as paisagens urbana e a rural. Para Santos (2008, p. 191), a paisagem representa:

[...] um conjunto de aspectos materiais, através dos quais a cidades se apresenta aos nossos olhos, ao mesmo tempo como entidade concreta e como organismo vivo. Compreende os dados do presente e os do passado recente ou mais antigo, mas também compreende elementos inertes (patrimônio imobiliário) e elementos móveis (as pessoas e as mercadorias).

Podemos observar que não há uma unidade acerca do conceito de cidade. As várias definições não são excludentes, mas representam às diferentes concepções teóricas de autores e épocas distintas, os quais enfocam diferentes vertentes do mesmo objeto em análise. 
Portanto, entender a cidade como um trunfo, é entender a sua dinâmica territorial, o seu crescimento urbano e populacional, e junto com esse crescimento vem os equipamentos básicos necessários ao atendimento das demandas da população, graças a maior autonomia e gestão de recursos financeiros destinados diretamente ao município.

\section{CONSIDERAÇÕES FINAIS}

Conforme visto durante todo o exposto, os eventos sociais e culturais são considerados como os principais agentes que visam consubstanciar a criação e a formação de um município, desde a implementação dos primeiros indícios para a constituição de um simples povoado, evoluindo até a emancipação política e, posteriormente, esses eventos continuam sendo necessários para o desenvolvimento do espaço intraurbano e toda a expansão no território municipal.

O município de Triunfo vivenciou eventos sociais desde o seu processo de surgimento como um pequeno povoado até a sua constituição vila e, posteriormente, à categoria de município. A sua emancipação política, no ano de 1961, torna-se o marco para o processo de urbanização e expansão da malha urbana desta cidade. A partir de então, constatamos um ritmo mais acelerado do desenvolvimento intraurbano, recebendo investimentos direto e indiretamente do Governo Federal, Estadual e Municipal. Contudo, são nas ações da população, que observamos uma das principais dinâmicas para a formação do município e da expansão urbana.

Por fim, esperamos que as análises e reflexões desenvolvidas neste trabalho sirvam como fonte de estudo para todos que se interessarem pelos processos de formação socioespacial e de expansão urbana da cidade de Triunfo, bem como pela análise do crescimento urbano, além da história desse município. 


\section{REFERÊNCIAS}

ABREU, W. E. A. São João na colônia e no império: fazenda, povoado e vila (1691-1889). Teresina-PI: Halley S.A., 2015. 394 p., il.

ANDRADE, A. A. C. (org.). Triunfo em Picadas: e o fim da Confederação do Equador. Campina Grande: EDUFCG, 2008.

ANDRADE, E. V. L. “Os quarenta”: tradição e identidade de uma comunidade negra na cidade de Triunfo-PB da década de 1950 aos dias atuais. 2013. [Monografia] - Universidade Federal de Campina Grande, Cajazeiras, 2013.

BEZERRA, J. da S. Novos municípios, velhas políticas: práticas de emancipação distrital e estratégicas de reprodução política na Paraíba. 2016. Tese (Doutorado) - Universidade Federal de Pernambuco, Recife, 2016.

BRASIL. Ministério de Integração Nacional. Anteprojeto de lei. Plano diretor participativo de Triunfo-PB. Projeto São Francisco: água a quem tem sede. Brasília: DF, 2012.

CARLOS, A. F. A. A cidade. 8. ed. São Paulo: Contexto, 2007.

CARLOS, A. F. A. O espaço urbano: novos escritos sobre a cidade. São Paulo: Labur Edições, 2007.

CORRÊA, R. L. A rede urbana. São Paulo: Ática, 1989.

CORRÊA, R. L. Globalização e Reestruturação da rede urbana: uma nota sobre pequenas cidades. Rio de Janeiro: LAGET/UFRJ, ano 4, n. 6, jan./jun. 1999.

HELIODORO, P. Padre Mestre Inácio Rolim: Um trecho da colonização do Norte brasileiro e o Padre Inácio Rolim. 2. ed. Atual. Teresina: Gráfica Estado do Piauí - Impressora e Editora Ltda, 1991.

INSTITUTO BRASILEIRO DE GEOGRAFIA E ESTATÍSTICA - IBGE. Sinopse do censo demográfico 2010 Paraíba. Disponível em:

https://censo2010.ibge.gov.br/sinopse/index.php?uf=25\&dados=8. Acesso em: 12 jan. 2021.

LIMA, J. D. Expansão urbana na cidade de Triunfo-PB. 2013. [Monografia]. Universidade Federal de Campina Grande, Cajazeiras, 2013.

LOPES, D. M. F.; HENRIQUE, W. Cidades médias e pequenas: teorias, conceitos e estudos de caso. Salvador: SEI, 2010.

MANGUEIRA, D. Os Labirintos do Triunfo. 1. ed. Teresina: Halley, 2011. 
MARX, K. \& ENGELS, F. A Ideologia Alemã. São Paulo: Moraes, 1984 [original: 1846].

MENDONÇA. T. Portal São Francisco. Urbanização no Brasil, 2018. Disponível em: https://www.portalsaofrancisco.com.br/geografia/urbanizacao-no-brasil . Acesso em: 5 jan. 2021.

PARAÍBA. Lei no 2 367, de 22 de dezembro de 1961. Cria o município de Triunfo e dá outras providências. João Pessoa, 1961. Disponível em:

http://sapl.al.pb.leg.br:8080/sapl/sapl_documentos/norma_juridica/2017_texto_integral. Acesso em: 22 dez. 2020.

SANTOS, M. A urbanização brasileira. 5. ed. São Paulo: Editora da Universidade de São Paulo, 2008.

VASCONCELOS, P. A. A cidade, o urbano, o lugar. Revista Geousp Espaço e Tempo, [S.l.], v.3, n.2, p. 11-15, 2006. Disponível em:

https://www.revistas.usp.br/geousp/article/view/123359. Acesso em: 20 dez. 2020.

WEBER, Max. The City. New York: The Free Press, 1958 [original: 1921]. 